\title{
Torrefaction of Barley Straw for the Co-Production of Energy and Adsorbent Materials
}

\author{
Ioanna Salapa, Panagiotis Haralampous, Georgios Giakoumakis, Antonios Nazos, Dimitrios Sidiras \\ Lab. Simulation of Industrial Processes, Dep. Industrial Management and Technology, University of Piraeus \\ 80 Karaoli \& Dimitriou, GR 18534 Piraeus, Greece \\ isalapa@unipi.gr; panosh@windowslive.com; giakourgos@gmail.com; anazos@yahoo.gr; sidiras@unipi.gr
}

\begin{abstract}
The purpose of this study was first to examine and then to maximize, the adsorbency of torrefied barley straw, in order to remove basic dyes like Methylene Blue (MB) from wastewater. On the other hand, the effect of the torrefaction process on the heating value of the material was investigated. Moderate modification conditions $\left(220^{\circ} \mathrm{C}, 20 \mathrm{~min}\right)$ were found to maximize adsorbency of modified barley straw. The experimental data were simulated by a pseudo-second order kinetic model. The torrefaction also significantly enhanced the higher heating value of the pretreated barley straw compared to the untreated material. Specifically, the calorific value increased from $16.1 \mathrm{MJ} / \mathrm{kg}$ to $19.4 \mathrm{MJ} / \mathrm{kg}$ for sample torrefied at $240{ }^{\circ} \mathrm{C}$ during $40 \mathrm{~min}$. Consequently, the torrefaction of barley straw leads to the coproduction of material with enhanced energy content in combination with improved adsorption capacity. The coproduction of energy and adsorbents from lignocellulosic biomass takes into account (i) the biorefinery (more than one product) and (ii) the Industrial Ecology concept (using solid waste to clean wastewater pollution).
\end{abstract}

Keywords: Biomass, Torrefaction, Adsorbent, Higher Heating Value.

\section{Introduction}

Lignocellulosics constitutes the most abundant source of unutilized biomass and their availability does not necessarily impact land use. There are several types of raw materials that are differentiated by their origin, composition and structure. Forest woody feedstocks (softwoods and hardwoods), agricultural residues, herbaceous and municipal solid wastes are some of those types. Over the years there have been several approaches on its efficient use and some of them will be presented herein.

A very appealing way to exploit the agricultural wastes is via pulping, refining and bleaching, of those residues, for papermaking. Several kinds of non-wood lignocellulosic agricultural remains have been investigated of which wheat, rice bagasse and barley straw were the most promising [1]. Another approach suggests the use of lignocellulosic biomass as low cost alternative adsorbents for the removal of water pollutants like dyes. Some of the most commonly used, for dye wastewater treatment, adsorbents are: alumina, silica gel, zeolites and last but not least activated carbon [2]. Various agricultural by-products like grapefruit peel [3], banana peel [4], pineapple stem [4], garlic peel [5], rice husk [7] and others have been studied for their adsorption capacity. Finally the most popular use is the production of energy and value-added materials.

Torrefaction is a relatively mild thermochemical process that involves heating the biomass at $250-350{ }^{\circ} \mathrm{C}$ in an inert atmospheric condition and at a low heating rate (residence time of $10 \mathrm{~min}-1 \mathrm{~h}$ ). The product obtained strongly depends on the experimental conditions applied during the process. In general, water and some volatile organic compounds with low calorific values are released from the native biomass converting the organic matter into high energy density product, which can be successfully used as input feedstock for thermochemical process for the production of biofuels, electricity and/or heat and biochemicals [8]. Torrefaction also increases the grindability characteristics and subsequently decreases the grinding cost [9-11]. Grinding is regarded as one of the most energy-intensive processes during pelletization (densification), fast pyrolysis, gasification, biochemical conversion, among other processes [12]. Torrefied products are also hydrophobic, this makes the torrefied product to be easily handled and convenient for storage and transportation [13].

The purpose of this study is to examine the effect of the torrefaction pretreatment on the higher heating value of the derived product as compared to the untreated barley straw. Moreover, it was investigated the feasibility of using this modified straw to remove basic dyes like MB from substitute wastewater. The controlling mechanisms of adsorption process such as 
chemical reaction, diffusion control or mass transfer coefficient were employed to determine kinetic models. The adsorption kinetics study illustrates the rate of the solute uptake which controls the residence time of the adsorbate at the solution interface. Thus, information on the solute uptake is prerequisite for choosing the best operating conditions for the full-scale batch [14-15]. Over the years, many models have been proposed to elucidate the mechanism of adsorption. Three of the most popular the pseudo-first-order model [16], the pseudo-second-order model [17] and the intra-particle kinetic model [18] are presented herein.

\section{Materials and Methods}

\subsection{Materials}

Barley straw (Hordeum Vulgare L.) was obtained from Beotia, Greece. It was chopped in small pieces and the fraction with sizes $2-3 \mathrm{~cm}$ (representing more than $95 \%$ of the raw total barley straw) was collected by sieving. This fraction was preferred because it is more appropriate for the process's scale up. The straw was ambient dried and the moisture content reduced to $8 \%$.

The dye used was MB with a chemical formula of C16H18ClN3S.xH2O and $373.910^{-3} \mathrm{~kg} \mathrm{~mol}^{-1}$ molecular weight. A stock solution was prepared by dissolving $5 \mathrm{~g}$ of $\mathrm{MB}$ in $25 \mathrm{~L}$ distilled water. Working solutions were 1.6-156 mg L $\mathrm{L}^{-1}$. MB concentrations were analyzed by measuring the absorbent values in each experiment with a HACH DR6000 UV-VIS spectrophotometer at $\lambda=664 \mathrm{~nm}$.

\subsection{Torrefaction Procedure}

A total of three pretreatment temperatures 200,220 and $240{ }^{\circ} \mathrm{C}$ and residence times of 20,40 and 60 min were examined. In each experiment, $5 \mathrm{~g}$ of barley straw were placed on a ceramic crucible and then in the oven (Thermolyne model 47900 ). After the specified residence time period (counted from the sample temperature reached the torrefaction temperature), the crucible was removed from the oven and saved in a desiccator. When the solid was cooled, it was weight and stored in plastic sealed buckets for further analyses.

\subsection{Adsorption Kinetic Studies}

Adsorption rate batch experiments were conducted in a 2-L glass totally mixed reactor equipped with a twisted blade agitator type, operating at $450 \mathrm{rpm}$, for maintaining the lignocellulosic material in suspension. The reactor, containing $\mathrm{V}=$ $1 \mathrm{~L}$ aqueous solution of dye was placed in a water bath to maintain constant temperature at the desired level. The adsorbent mass was $\mathrm{m}=1 \mathrm{~g}$, the temperature was $23^{\circ} \mathrm{C}$, the initial concentration of $\mathrm{MB}$ was $\mathrm{C}_{0}=12 \mathrm{mg} \mathrm{L}^{-1}$.

\subsection{Higher Heating Value}

The determination of high heating value was performed using a Parr 1341 calorimeter. $0.5 \mathrm{~g}$ of the material was put in the combustion vessel which was subsequently charged with oxygen to 25 atmospheres. The calorimeter bucket was filled with $2000 \mathrm{~mL}$ of distilled water. The bucket was attached in the calorimeter and then the combustion vessel was put in the bucket. The two ignition lead wires were pushed into the terminal sockets on the bombs' head. The cover was set on the jacket and the stirrer was turned manually to ensure that runs freely. If it turns normally then the drive belt is slipped onto the pulleys and the motor is started. The Temperature indications were taken via the 6775 Parr Digital Thermometer each minute for 5 minutes in order to achieve equilibrium into the calorimeter. At the start of the sixth minute the ignition button was pushed and temperature measurements were taken each minute until the temperature was stable again. The rise of the temperature will be rapid during the first minutes and slow when we get close to the equilibrium.

\section{Results and Discussion}

\subsection{Effect of Torrefaction on Higher Heating Value (HHV)}

In Table 1, the mass and energy efficiencies of torrefaction, the higher heating value and the relationship of heating values between native and torrefied biomass are presented. The results show that barley straw retains its energy potential 
Table 1: Mass yield, higher heating value and energy yield for untreated and torrefied barley straw.

\begin{tabular}{|c|c|c|c|c|}
\hline Time (min) & $\begin{array}{c}\text { Mass yield, } n_{m} \\
(\%)\end{array}$ & $\begin{array}{c}\text { Higher heating value } \\
(\mathrm{MJ} / \mathrm{kg})\end{array}$ & $\begin{array}{c}\text { Energy yield } n_{e} \\
(\%)\end{array}$ & $\begin{array}{l}\text { Ratio of } \\
\text { HHV }\end{array}$ \\
\hline Untreated & 100 & 16.1 & 100 & 1.00 \\
\hline \multicolumn{5}{|c|}{ Pretreated at $200{ }^{\circ} \mathrm{C}$} \\
\hline 20 & 90.1 & 16.3 & 91.2 & 1.01 \\
\hline 40 & 86.2 & 17 & 91.0 & 1.06 \\
\hline 60 & 83.7 & 16.5 & 85.7 & 1.02 \\
\hline \multicolumn{5}{|c|}{ Pretreated at $220^{\circ} \mathrm{C}$} \\
\hline 20 & 81.0 & 16.9 & 85.0 & 1.05 \\
\hline 40 & 80.2 & 16.8 & 83.7 & 1.04 \\
\hline 60 & 80.6 & 16.9 & 84.6 & 1.05 \\
\hline \multicolumn{5}{|c|}{ Pretreated at $240{ }^{\circ} \mathrm{C}$} \\
\hline 20 & 58.2 & 19 & 68.6 & 1.18 \\
\hline 40 & 51.4 & 19 & 60.6 & 1.18 \\
\hline 60 & 50.1 & 19.4 & 60.4 & 1.20 \\
\hline
\end{tabular}

during torrefaction although it loses mass. Most weight loss occurs during the torrefaction at high temperatures. The higher the torrefaction temperature, the lower is the mass yield. An increase in pretreatment time may also have this effect but mass yield is less sensitive to time.

The torrefaction also significantly changes the higher heating value of the untreated barley straw. Specifically, the calorific value increased from $16.1 \mathrm{MJ} / \mathrm{kg}$ to $19.4 \mathrm{MJ} / \mathrm{kg}$ for sample torrefied at $240{ }^{\circ} \mathrm{C}$ during $40 \mathrm{~min}$. This relationship between the calorific values of the untreated and torrefied biomass is sometimes called energy increase or energy densification ratio and it is always greater than unity. Thus, torrefaction process converts raw biomass into a high energy density feedstock. Each sample was performed in duplicate, with the average value reported. The standard deviation for HHV was $1.9 \%$.

An additional parameter presented in Table 1 is the energy yield $\left(n_{e}\right)$ that is calculated based on the mass yield, using the following equation $[19,20]$ :

$$
n_{e}=n_{m}\left(\frac{H H V_{\text {torrefied }}}{H H V_{\text {untreated }}}\right)
$$

where $n_{m}$ is the mass yield and $n_{e}$ is the energy yield (\%) of the torrefied barley straw.

Energy yield indicates the total energy preserved in the torrefied biomass. Biomass torrefied at lower temperatures are superior with respect to energy yield, which was expected since this parameter was strongly dependent on mass yield which was significantly affected by process temperature.

\subsection{Kinetics of Adsorption}

Kinetic models' equations: The kinetics of adsorption of MB on untreated and torrefied barley straw has been extensively studied using following kinetic equations. The widely used Lagergren equation [16] is shown below:

$$
q_{t}=q_{e}\left(1-e^{-k_{1} t}\right)
$$

where $q_{e}$ and $q_{t}$ are the amounts of $\mathrm{MB}$ adsorbed per unit mass of the adsorbent (in $\mathrm{mg} \mathrm{g}^{-1}$ ) at equilibrium time $(\mathrm{t} \rightarrow \infty)$ and adsorption time $t$, respectively, while $k$ is the pseudo-first order rate constant for the adsorption process (in $\min ^{-1}$ ). 
Table 2: Pseudo-first-order kinetic model parameters.

\begin{tabular}{|c|c|c|c|}
\hline Time (min) & $k\left(\mathrm{~min}^{-1}\right)$ & $q_{e}\left(\mathrm{mg} \mathrm{g}^{-1}\right)$ & SEE \\
\hline Untreated & 0.053 & 6.79 & 0.377 \\
\hline Pretreated at $200^{\circ} \mathrm{C}$ & 0.043 & 7.43 & 0.433 \\
\hline 20 & 0.042 & 8.73 & 0.365 \\
\hline 40 & 0.049 & 9.28 & 0.426 \\
\hline 60 & 0.058 & 9.86 & 0.476 \\
\hline Pretreated at $220^{\circ} \mathrm{C}$ & 0.052 & 9.18 & 0.476 \\
\hline 20 & 0.038 & 8.46 & 0.345 \\
\hline 40 & 0.059 & 7.24 & 0.533 \\
\hline 60 & 0.087 & 8.64 & 0.502 \\
\hline Pretreated at $240^{\circ} \mathrm{C}$ & 0.035 & 6.58 & 0.163 \\
\hline 40 & \multicolumn{5}{|l}{} \\
\hline 60 &
\end{tabular}

Furthermore,

$$
q_{e}=\left(C_{0}-C_{e}\right) V / m \text { and } q_{t}=\left(C_{0}-C\right) V / m
$$

where $\mathrm{C}, \mathrm{C}_{0}, \mathrm{C}_{\mathrm{e}}$ are the concentrations of $\mathrm{MB}$ in the bulk solution at time t, 0 , and $\infty$, respectively, while $\mathrm{m}$ is the weight of the adsorbent used (in $\mathrm{g}$ ), and $\mathrm{V}$ is the solution volume (in $\mathrm{mL}$ ). Further modification of eq. (3) in logarithmic form gives:

$$
\ln \left(q_{e}-q_{t}\right)=\ln q_{e}-k \cdot t
$$

The commonly used second-order kinetic model [17] is as follows:

$$
q_{t}=q_{e}-\left[q_{e}^{-1}+k_{2} t\right]^{-1}
$$

Tables 2, 3 and 4 show that all three models give a good correlation to experimental data. However, based on the SEE values, it was observed that the pseudo-second-order kinetic model provides the best fit to the data for all modified wheat straw adsorbents, because the SEE values were at least $20 \%$ lower, than the values obtained for pseudo-first-order and intraparticle kinetic models. The lower the SEE, the lower the difference of the q calculated by the model from the experimentally measured $q[15,21]$. Also, it was verified that the $\mathrm{q}_{\mathrm{e}}$ values found in the pseudo-second-order were closer to the experimental $q_{e}$ values, when compared with the presented kinetic models. These results indicate that the pseudo-second-order kinetic model should explain the adsorption process.

In Figures 1 and 2 is presented the effect of torrefaction temperature and time on the adsorption of MB by modified pretreated barley straw, based on the pseudo-second order kinetic model. More specifically, the effect of time when the torrefaction temperature is occurred at $220{ }^{\circ} \mathrm{C}$ is presented in Fig. 1 according to the pseudo-second kinetic model. Overall the adsorption capacity of the modified straw was improved compared to the untreated. However, when more severe process conditions are employed the adsorption capacity decreases. 
Table 3: Pseudo-second-order kinetic model parameters.

\begin{tabular}{|c|c|c|c|}
\hline Time (min) & $k_{2}\left(\mathrm{~g} \mathrm{mg}^{-1} \mathrm{~min}^{-1}\right)$ & $q_{e}(\mathrm{mg} / \mathrm{g})$ & SEE \\
\hline Untreated & 0.008 & 8.11 & 0.232 \\
\hline Pretreated at $200{ }^{\circ} \mathrm{C}$ & 9.10 & 0.305 \\
\hline 20 & 0.005 & 10.85 & 0.199 \\
\hline 40 & 0.004 & 11.25 & 0.220 \\
\hline 60 & 0.005 & 11.65 & 0.22 \\
\hline Pretreated at $220^{\circ} \mathrm{C}$ & 10.99 & 0.26 \\
\hline 20 & 0.006 & 10.69 & 0.20 \\
\hline 40 & 0.006 & 8.44 & 0.347 \\
\hline 60 & 0.004 & 9.75 & 0.227 \\
\hline Pretreated at $240^{\circ} \mathrm{C}$ & 0.009 & 8.61 & 0.109 \\
\hline 20 & 0.013 & 0.004 &
\end{tabular}

Table 4: Intra-particle kinetic model parameters

\begin{tabular}{|c|c|c|c|}
\hline Time (min) & $k_{2}\left(\mathrm{~g} \mathrm{mg}^{-1} \mathrm{~min}^{-1}\right)$ & $q_{e}(\mathrm{mg} / \mathrm{g})$ & SEE \\
\hline Untreated & 0.008 & 8.11 & 0.232 \\
\hline Pretreated at 200 & ${ }^{\circ} \mathrm{C}$ & 9.10 & 0.305 \\
\hline 20 & 0.005 & 10.85 & 0.199 \\
\hline 40 & 0.004 & 11.25 & 0.220 \\
\hline 60 & 0.005 & 9.10 & 0.305 \\
\hline Pretreated at $220^{\circ} \mathrm{C}$ & 10.85 & 0.199 \\
\hline 20 & 0.005 & 11.25 & 0.220 \\
\hline 40 & 0.004 & 8.44 & 0.347 \\
\hline 60 & 0.005 & 9.75 & 0.227 \\
\hline Pretreated at 240 ${ }^{\circ} \mathrm{C}$ & 0.009 & 8.61 & 0.109 \\
\hline 20 & 0.013 & 0.004 &
\end{tabular}

The plot of MB adsorption versus contact time for selected experiments is shown in Figure 2. The materials were picked based on the pretreatments' severity (moderate conditions based on process time) but also including the untreated barley straw. Consequently, the effect of the temperature process could be investigated. At all cases the torrefaction process increased the adsorption capacity of the barley straw. Yet, at the most severe process temperature the adsorption capacity decreased. 


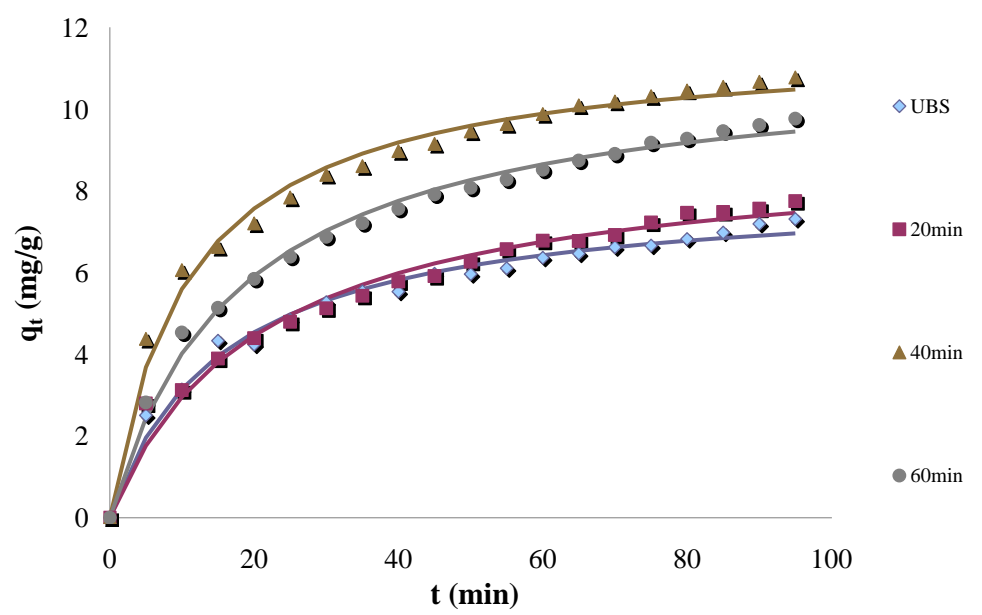

Fig. 1: Curves according to the Pseudo-second-order kinetic model for untreated and torrefied at $220{ }^{\circ} \mathrm{C}$ for 20,40 and 60 min barley straw.

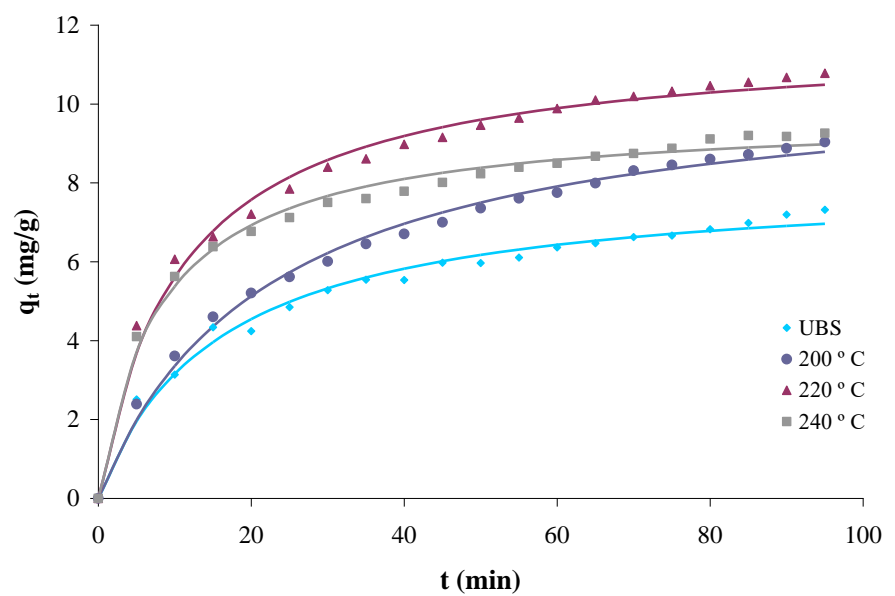

Fig. 2: Curves according to the Pseudo-second-order kinetic model for untreated and torrefied for 40 min at 200, 220 and $240{ }^{\circ} \mathrm{C}$ barley straw.

\section{Conclusion}

Torrefaction conditions were investigated herein for enhancing barley straw higher heating value and adsorbency. The calorific value increased and reached maximum for the sample torrefied at the most severe conditions ( $240{ }^{\circ} \mathrm{C}$ for $\left.60 \mathrm{~min}\right)$. Whereas, moderate modification conditions were found to maximize adsorbency of torrefied barley straw for the removal of MB from wastewater. The adsorption kinetic data were found to follow the pseudo-second-order kinetic model. In conclusion, modified barley straw could be used instead of expensive commercial activated carbon for the removal of MB from aqueous solutions as well as material suitable for energy production.

\section{Acknowledgements}

Financial support provided by the Research Centre of the University of Piraeus is kindly acknowledged.

\section{References}

[1] D. Kaur, N. K. Bhardwaj, and R. K. Lohchab, "Prospects of rice straw as a raw material for paper making," Waste Manag., vol. 60, pp. 127-139, 2017.

[2] V. K. Gupta, Suhas, “Application of low-cost adsorbents for dye removal - A review," J. Envir. Manag., vol. 90, pp. 2313-2342, 2009. 
[3] A. Saeed, M. Sharif, M. Iqbal, “Application potential of grapefruit peel as dye sorbent: kinetics, equilibrium and mechanism of crystal violet adsorption," J Hazard Mater, vol. 179, no. 1, pp. 564-72, 2010.

[4] G. Annadurai, R. S. Juang, D. J. Lee, "Use of cellulose-based wastes for adsorption of dyes from aqueous solutions," J Hazard Mater, vol. 92, no. 3, pp. 263-74, 2002.

[5] B. Hameed, R. Krishni, S. Sata, "A novel agricultural waste adsorbent for the removal of cationic dye from aqueous solutions," J Hazard Mater, vol. 16, vol. 21, pp. 305-311, 2009.

[6] B. Hameed, A. Ahmad, "Batch adsorption of methylene blue from aqueous solution by garlic peel, an agricultural waste biomass," J Hazard Mater, vol. 164, no. 2, pp. 870-875, 2009.

[7] V. Vadivelan, K. V. Kumar, "Equilibrium, kinetics, mechanism, and process design for the sorption of methylene blue onto rice husk," J Colloid Interface Sci, vol. 286, no. 1, pp. 90-100, 2005.

[8] M. A. Martín-Lara, A. Ronda, M. C. Zamora, and M. Calero, "Torrefaction of olive tree pruning: Effect of operating conditions on solid product properties," Fuel, vol. 202, pp. 109-117, 2017.

[9] D. Medic, M. Darr, A. Shah, B. Potter, J. Zimmerman, "Effects of Torrefaction process parameters on biomass feedstock upgrading," Fuel, vol. 91, pp. 147-154, 2012.

[10] M. J. C. van der Stelt, H. Gerhauser, J. H. A. Kiel, K. J. Ptasinski, "Biomass upgrading by torrefaction for the production of biofuels: a review," Biomass Bioenergy, vol. 35, 3748- 3762, 2011.

[11] G. J. Wang, Y. H. Luo, J. Deng, J. H. Kuang, Y. L. Zhang, "Pretreatment of biomass by Torrefaction," Chin. Sci. Bull., vol. 56, no. 14, pp. 1442-1448, 2011.

[12] J. Koppejan, S. Sokhansanj, S. Melin, S. Madrali, Status Overview of Torrefaction Technologies. International Energy Agency (IEA) Bioenergy Task 32 report, 2012.

[13] R. H. H. Ibrahima, I. D. Leilani, J. M. Jonesa, A. Williams, "Physicochemical characterization of torrefied biomass," J. Anal. Appl. Pyrolysis, vol. 103, pp. 21-30, 2013.

[14] M. T. Yagub, T. K. Sen, S. Afroze, and H. M. Ang, "Dye and its removal from aqueous solution by adsorption: A review," Adv. Colloid Interface Sci., vol. 209, pp. 172-184, 2014.

[15] T. Calvete, E.C. Lima, N. F. Cardoso, J. C. P. Vaghetti, S. L. P. Dias, F. A. Pavan, "Application of carbon adsorbents prepared from Brazilian-pine fruit shell for the removal of reactive orange 16 from aqueous solution: kinetic, equilibrium, and thermodynamic studies," J. Environ. Manag., vol. 91, pp. 1695-1706, 2010.

[16] S. Lagergren, "Zur theorie der sogenannten adsorption gelöster stoffe," Kungliga Svenska Vetenskapsakademiens, Handlingar, vol. 24, pp. 1-39, 1898.

[17] Y. S. Ho, G. McKay, "Pseudo-second-order model for sorption processes," Process Biochem, vol. 34, pp. 451-65, 1999.

[18] W. J. Weber, J. C. Morris, "Kinetics of adsorption on carbon from solution," J. Sanit. Eng. Div. Am. Soc. Civil Eng., vol. 89, pp. 31-59, 1963.

[19] W. H. Chen, K. M. Lu, C. M. Tsai, "An experimental analysis on property and structure variations of agricultural wastes undergoing torrefaction,” Appl. Energ. vol. 100, pp. 318-25, 2012.

[20] W. Park S, C. H. Jang, Baek KR, J. K. Yang, "Torrefaction and low-temperature carbonization of woody biomass: Evaluation of fuel characteristics of the products," Energy, vol. 45, pp. 676-85, 2012.

[21] B. Royer, N. Cardoso, E. Lima, J. C. P. Vaghetti, N. M. Simon, T. Calvete, R. C. Veses, "Applications of Brazilian pine-fruit shell in natural and carbonized forms as adsorbents to removal of methylene blue from aqueous solutionsKinetic and equilibrium study," J. Hazard. Mater., vol. 164, no. 2-3, pp. 1213-1222, 2009. 